\title{
1. The economics and epidemiology of epidemics and pandemics
}

\subsection{THE RISE OF COVID-19: EPIDEMIC TO PANDEMIC AND PERHAPS ENDEMIC}

The COVID-19 pandemic, also known as the coronavirus pandemic, is caused by severe acute respiratory syndrome coronavirus 2 (SARS-CoV-2). The virus is primarily spread between people as a result of close contact via small droplets produced by coughing, sneezing and exhaling. Infection may also occur when people touch a contaminated surface (fomite) and then touch their faces, enabling the virus to reach the respiratory system via nose, mouth or eyes. According to a systematic review of the scientific literature, face touching occurs at least twice as frequently as the often-cited figure of 23 times an hour (Rahman et al., 2020).

The World Health Organization (2020a) describes the transmission of the virus as follows: 'Transmission of SARS-CoV-2 can occur through direct, indirect, or close contact with infected people through infected secretions such as saliva and respiratory secretions or their respiratory droplets, which are expelled when an infected person coughs, sneezes, talks or sings.' The WHO also refers to airborne transmission, which is caused by the dissemination of droplet nuclei (aerosols) that remain infectious when suspended in air over long distances and time. Moreover, the virus has been detected in biological samples, including the urine and faeces of some patients - however, the WHO suggests that no published reports confirm transmission through faeces or urine.

In December 2019, a cluster of pneumonia cases with unknown source were recorded in the city of Wuhan, China. These cases were reported to the WHO on 31 December 2019. The new virus was identified in January 2020, and on 11 January, Chinese state media reported the first known death from an illness caused by the virus, which had infected dozens of people. The 61-year-old man who died was a regular customer at the wet market in Wuhan. On 20 January 2020, the first confirmed cases outside mainland China were detected in Japan, South Korea and Thailand. The first confirmed case in the US was declared the following day, as a man in his 30 s developed symptoms after returning to 
Washington State from a trip to Wuhan. On 23 January, the Chinese authorities closed off Wuhan by cancelling planes and trains leaving the city, and suspending buses, subways and ferries within the city. On 30 January, amid thousands of new cases in China, a 'public health emergency of international concern' was officially declared by the WHO. This is a formal declaration of 'an extraordinary event which is determined to constitute a public health risk to other States through the international spread of disease and to potentially require a coordinated international response', formulated when a situation arises that is 'serious, sudden, unusual or unexpected'. The situation 'carries implications for public health beyond the affected state's national border' and 'may require immediate international action' (World Health Organization, 2019a).

On 11 February 2020, the WHO proposed an official name for the disease caused by the coronavirus, COVID-19, an acronym that stands for 'Coronavirus Disease 2019'. The name makes no reference to any of the people, places, or animals associated with the virus, which was intentional to avoid stigma (recall that Donald Trump always referred to the coronavirus as the 'China virus'). One month later, on 11 March, the WHO declared a pandemic, producing big losses in stock markets worldwide. On 14 April, the International Monetary Fund warned that the global economy was headed for its worst downturn since the Great Depression. The IMF predicted that the world economy would contract by $3 \%$ in 2020, a reversal from its earlier, pre-pandemic forecast that the world economy would grow by $3.3 \%$. That happened as countries scrambled to implement public health measures, with dire economic consequences.

By early May 2020, a backlash was building against China for its alleged mishandling of the crisis. Australia called for an inquiry into the origins of the virus. In Britain and Germany, new questions were raised about the advisability of using the Chinese tech-giant Huawei for new 5G systems. President Trump continued to blame China for the outbreak and sought ways to punish the 'communist state'. The word 'reparations' became popular as the fingers pointed to China as the cause of the pandemic, either through mishandling and misinformation or because the virus had been accidently released from a lab in Wuhan.

Conspiracy theories began to emerge, some blaming China and others blaming the US for the pandemic. In February 2021, a fact-finding mission of the WHO investigating the virus's origins concluded a visit to Wuhan. On that occasion, Dr. Peter Embarek of the WHO said that it was 'extremely unlikely' that the coronavirus leaked from a lab in Wuhan, and that it was more likely that the virus had jumped to humans from an animal (Talmazan and Smith, 2021). The speculation that the virus was either manufactured at or accidentally leaked from a lab at the Wuhan Institute of Virology was partially fuelled by former US president Donald Trump. 
On 13 May 2020, Dr. Mike Ryan, the head of the WHO's health emergencies program, said that the virus may become 'just another endemic virus in our communities' and that 'this virus may never go away'. He also tamped down expectations that the invention of a vaccine would provide a quick and complete end to the global crisis. Starting with an outbreak in Wuhan, COVID-19 has progressed from an epidemic to a pandemic, and it will perhaps remain as endemic (World Health Organization, 2020b). In February 2021, Nature published the results of a survey showing that 'scientists expect the virus that causes COVID-19 to become endemic, but it could pose less danger over time' (Phillips, 2021).

\subsection{SOME PRINCIPLES OF INFECTIOUS DISEASES}

Infectious diseases, which are ever present amongst us, are spread by either bacterial or viral agents (otherwise, the agents can be fungi or parasites). It is normal to observe infection cases below an expected threshold, but every now and then communities experience an outbreak, a new strain or a new disease that has a significant impact at either a local or global level. An outbreak is a greater-than-anticipated increase in the number of cases in a particular area - it can also be a single case in a new area. The terms describing an infectious disease are often used interchangeably in an erroneous manner. For example, distinction between the words 'pandemic', 'epidemic' and 'endemic' is blurred, particularly because the description of each of these terms changes as the underlying disease becomes more or less prevalent over time. The differences may refer to the spread and the rate of growth of new cases.

While the level of disease occurrence can be described in many ways, it is primarily defined by two measurable factors: (i) the pattern and speed by which a disease moves (the reproduction rate); and (ii) the size of the susceptible population (the critical community size). The terms may suggest that a specific threshold may be used to declare an outbreak, epidemic, or pandemic, but the distinction is often blurred, even among epidemiologists who are cautious about how they describe a disease event so that it is placed in the appropriate context. Certain terms can incite undue panic. One such example is the Zika outbreak of 2016, which triggered alarm in the US when a locally acquired disease occurred in 218 individuals in Florida and six people in Texas. Even with HIV, a disease that has spread across much of the planet, the term 'pandemic' has been increasingly replaced by 'epidemic', given the widespread distribution of effective treatment and declining rates in some previously hyper-prevalent regions. On the other hand, as influenza becomes more virulent year after year, public health officials commonly refer to seasonal outbreaks as pandemics, particularly given the $2009 \mathrm{H} 1 \mathrm{~N} 1$ outbreak that 
affected 60 million people in the US, resulting in 274,304 hospital admissions and 12,469 deaths.

Humanity has always encountered pandemics. The HIV/AIDS pandemic has killed over 30 million people since 1982. The 541 AD Plague of Justinian killed 25-50 million people in one year. The Black Death (Bubonic Plague) killed more than 75 million people during the period 1347-1351, perhaps more if the count includes (in addition to Europe) those who died in the Middle East, China and India. The Spanish flu pandemic of 1918 killed well over 50 million people in one year. The smallpox pandemic of the 20th century claimed more than 300 million lives. The ongoing tuberculosis pandemic continues to kill over 1.5 million people every year. It appears that the likelihood of pandemics has increased over the past century because of global travel and integration, urbanisation, changes in land use, and greater exploitation of the natural environment. It is likely that these trends will continue and intensify.

\subsection{SOME PRINCIPLES OF EPIDEMIOLOGY}

Epidemiology is the branch of medicine that deals with the incidence, distribution and control of diseases. The role of epidemiology is to determine disease prevalence (the proportion of people affected within a population) and incidence (the occurrence of a disease over a specific period of time). This information is vital for the direction of an appropriate public health response.

A basic tool of epidemiology is the epidemiological curve (or epi curve), which shows the numbers of new cases over time. The spread of a contagious disease does not follow an exponential curve, in the sense that cases do not rise exponentially over time, except at the beginning. What happens in reality is that new cases rise rapidly, peak, and then decline. During the spread of the disease, some patients (most patients in the case of COVID-19) recover, some (tragically) die, and uninfected people start taking measures to reduce the infection rate.

Figure 1.1 shows a typical epi curve, with intervals describing the growth of new cases. The investigation interval is initiated by investigating infection (in humans or animals anywhere in the world) that is judged to have potential implications for public health. The recognition interval starts with the identification of increasing numbers of human cases or clusters of infection anywhere in the world, particularly when the characteristics of the virus indicate greater potential for human-to-human transmission. The initiation interval begins when cases are confirmed anywhere in the world, with demonstrated efficient and sustained human-to-human transmission. The acceleration interval is indicated by a consistently increasing number of cases. The deceleration interval is indicated by a consistently declining number of cases. The preparation interval is characterised by low pandemic activity, although outbreaks might continue 
to occur in certain regions. This interval involves preparing for potential additional waves of infection.

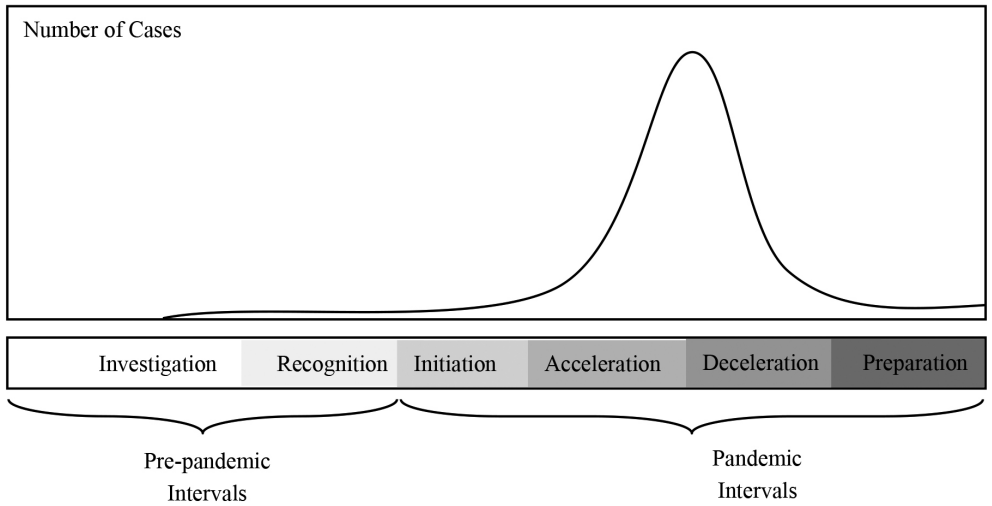

Figure 1.1 A typical epi curve

The simplest epidemiological model is the SIR model, which belongs to the family of compartmental models used for the mathematical representation of infectious diseases. According to this model, the population is assigned to three compartments: $S$ (susceptible), $I$ (infected) and $R$ (recovered or dead). The susceptible include everyone who is not infected yet or is disease free. The infected, who carry the virus, are capable of infecting other people. Those who recover or die do not infect anyone else. Because the number of deaths is negligible with respect to the total population, $R$ may be considered as the recovered only. People may move from one compartment to another: a susceptible person becomes infected, then recovers. Since the dynamics of an epidemic are faster 
than the dynamics of birth, the model is represented by following set of differential equations:

$$
\begin{aligned}
& \frac{d S}{d t}=-\frac{\beta I S}{N} \\
& \frac{d I}{d t}=\frac{\beta I S}{N}-\gamma I \\
& \frac{d R}{d t}=\gamma I
\end{aligned}
$$

where $t$ is time, $\beta$ is the rate at which the disease is transmitted from an infected to a susceptible, $\gamma$ is the reciprocal of the average duration of recovery, and $N=S+I+R$. In this model, the basic reproduction rate $\left(R_{0}\right)$ is the expected number of cases generated directly by one case in a population where all individuals are susceptible to infection. It is calculated as

$$
R_{0}=\frac{\beta}{\gamma}
$$

The model is dynamic, in the sense that the number in each compartment changes over time. With time, the number of susceptible falls rapidly as more of them are infected (a change from $S$ to $I$ ). In Figure 1.2, we can see how $S$, $I$ and $R$ change over time, in accordance with the set of differential equations. A modified version is the SEIR model, which has a fourth compartment, the exposed, who have already contracted the disease but the virus is still in the incubation period. In other words, the exposed are those who carry the virus without showing any symptoms.

\subsection{ECONOMIC AND FINANCIAL CONSEQUENCES OF PANDEMICS}

Pandemics lead to a significant increase in morbidity and mortality over a wide geographical area, in the process causing economic, social and political disruption. Economic damage can be caused through several channels, including short-term fiscal shocks and long-term negative shocks to economic growth. Individual behavioural changes, such as fear-induced aversion to workplaces and other public gathering venues are a primary cause of negative shocks to economic growth. Some pandemic mitigation measures can cause significant 


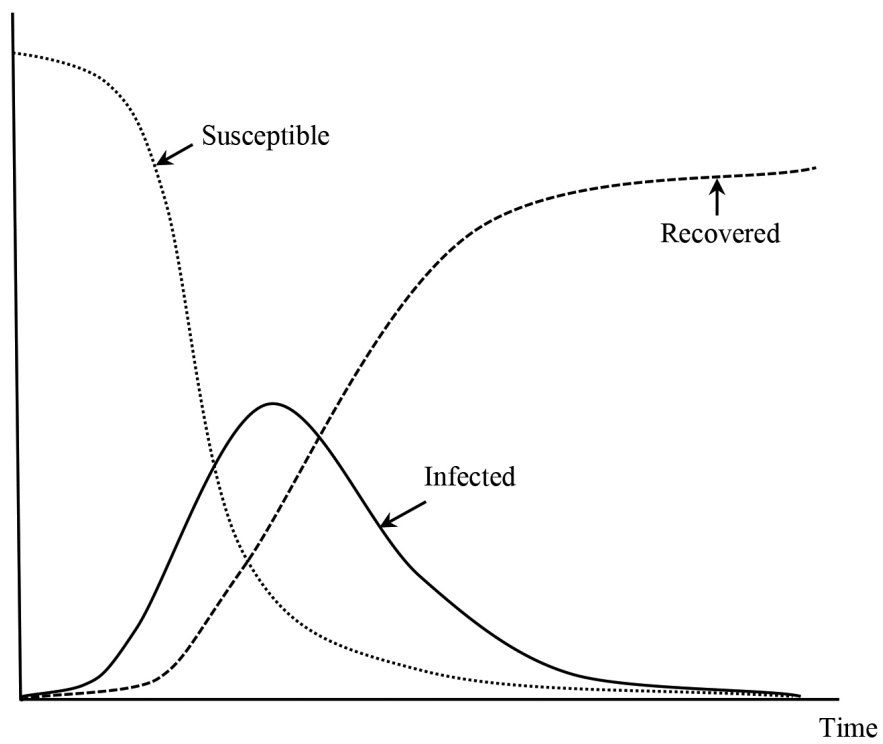

Figure 1.2 Prediction of the SIR model

social and economic disruption. In countries with weak institutions and political instability, pandemics can aggravate political stress and tension. In these contexts, outbreak response measures, such as quarantines, have sparked violence and tension between states and citizens.

A sizeable outbreak can overwhelm the healthcare system, limiting the capacity to deal with routine health issues, which aggravates the problem. Beyond shocks to the healthcare system, both the ill and their caretakers are forced to miss work, or if they go to work they are less effective, driving down productivity. Fear of infection can result in the closure of schools, factories, commercial establishments, means of transportation and public service venues, which disrupts economic and social activity. During a severe pandemic, all sectors of the economy (agriculture, manufacturing and services) face disruption, potentially leading to shortages, rapidly rising prices of staple goods and economic stress for households, firms and governments.

The direct fiscal impacts of pandemics are generally small relative to the indirect damage inflicted on economic activity and growth. Typically, the effect of aversive behaviour (such as the avoidance of travel, restaurants and 
public spaces, as well as prophylactic workplace absenteeism) exceeds the direct effect of absenteeism associated with morbidity and mortality. Negative effects on economic activity are driven directly by the reduction in the labour force caused by sickness and mortality and indirectly by fear-induced behavioural changes. In reference to the 2014 Ebola epidemic in West Africa, the World Bank (2014) notes the following:

Fear of association with others ... reduces labor force participation, closes places of employment, disrupts transportation, motivates some governments to close land borders and restrict entry of citizens from affected countries, and motivates private decision makers to disrupt trade, travel, and commerce by canceling scheduled commercial flights and reducing shipping and cargo services.

The indirect economic impact of pandemics has been quantified primarily through computable general equilibrium simulations. The simulations conducted by Burns et al. (2006) indicate that a severe pandemic could reduce world GDP by roughly 5\%. Country-specific estimates tell the same story. Smith et al. (2009) demonstrate that the impact of an influenza pandemic on the UK depends on the severity of the pandemic, such that a low-severity event could reduce GDP by up to $1 \%$, whereas a high-severity event could reduce GDP by 3-4\%. Thomas et al. (2015) show that economic disruption in low-income countries could be even greater - for example, the Ebola pandemic was so devastating for Sierra Leone that the growth rate went down to $-2 \%$ compared to $9 \%$ in the pre-Ebola period. The UNDP (2015) presents a comprehensive analysis of the economic impact of the Ebola pandemic by using the Solow-Swan growth model to analyse the macroeconomic impact of a temporary shock on the labour force and capital accumulation.

Table 1.1 provides a summary of some studies estimating the economic losses due to pandemics and epidemics, real and imaginary. The 1918-19 influenza pandemic produced six percentage points loss in GDP growth, according to Barro et al. (2020) and 18\% decline in manufacturing activity per year according to Correia et al. (2020). SARS produced a $0.1 \%$ decline in global GDP, according to Lee and McKibbin (2004), and 1-2 percentage points of Chinese growth, according to Hai et al. (2004). The losses that can be produced by a 1918-type pandemic have been estimated by Arnold et al. (2006), Burns et al. (2006) and Fan et al. (2016). Fan et al. (2016) consider the economic loss due to a pandemic by including the intrinsic value of lives lost, finding that the bulk of the expected annual loss from pandemics is driven by the direct cost of mortality, particularly in the case of low-probability, high-severity events. On the other hand, Arnold et al. (2006) estimate the loss in annual GDP growth to be $4.25 \%$, of which $2.25 \%$ is attributed to the supply-side effect and $2 \%$ to the demand-side effect. 
Table 1.1 Estimated economic effects of epidemics/pandemics

\begin{tabular}{|c|c|c|}
\hline Study & Epidemic/Pandemic & Economic Losses \\
\hline Lee and McKibbin (2004) & SARS, 2003 & $0.1 \%$ in global GDP in 2003 \\
\hline Hai et al. (2004) & SARS, 2003 & 1-2 percentage points of Chinese GDP growth \\
\hline Burns et al. (2006) & A 1918-type pandemic & $3.1 \%$ in annual global GDP growth \\
\hline Arnold et al. (2006) & A 1918-type pandemic & $\begin{array}{l}4.25 \% \text { in annual GDP growth ( } 2.25 \% \text { from the } \\
\text { supply side and } 2 \% \text { from the demand side })\end{array}$ \\
\hline Keogh-Brown et al. (2010) & An H1N1 pandemic & $1.4-6 \%$ in annual GDP growth \\
\hline World Bank (2014) & Ebola, 2014-16 & $\begin{array}{l}2.1 \% \text { GDP growth in Guinea, } 3.4 \% \text { in Liberia, } \\
3.3 \% \text { in Sierra Leone in the first year of the } \\
\text { epidemic }\end{array}$ \\
\hline Fan et al. (2016) & A 1918-type pandemic & $\begin{array}{l}0.4-1 \% \text { of GDP per year due to ex ante } \\
\text { prospects of a pandemic, } 86 \% \text { of which is due to } \\
\text { mortality and } 14 \% \text { to lost income }\end{array}$ \\
\hline $\begin{array}{l}\text { Global Preparedness } \\
\text { Monitoring Board (2019) }\end{array}$ & A 1918-type pandemic & $4.8 \%$ of annual global GDP \\
\hline Barro et al. (2020) & $\begin{array}{l}\text { Influenza pandemic, } \\
1918-19\end{array}$ & Six percentage points of GDP growth \\
\hline Correia et al. (2020) & $\begin{array}{l}\text { Influenza pandemic, } \\
1918-19\end{array}$ & $\begin{array}{l}18 \% \text { decline in manufacturing activity per } \\
\text { year }\end{array}$ \\
\hline
\end{tabular}

The adverse economic effects of pandemics are intertwined with their social and political effects. Price-Smith (2009) refers to evidence suggesting that pandemics can have significant social and political consequences, creating clashes between states and citizens, eroding state capacity, driving population displacement, and heightening social tension and discrimination. Diamond (2009) argues that severe pandemics have been associated with significant social and political upheaval, driven by mortality shocks and the resulting demographic shifts. As an example, he refers to deaths arising from the introduction of smallpox and other diseases to the Americas, which led directly to the collapse of many Indigenous societies.

Epidemics and pandemics can amplify existing political tensions and spark unrest, particularly in fragile states with legacies of violence and weak institutions. During the 2014 West Africa Ebola epidemic, steps taken to mitigate the transmission of the disease (such as the imposition of quarantines and curfews) were viewed with suspicion by segments of the public and opposition political leaders. According to McCoy (2014), this led directly to riots and violent clashes with security forces. Tension between previously warring factions in Liberia, which re-emerged early in the epidemic, were linked to threats to healthcare workers as well as attacks on public health personnel and facilities. Quarantine in opposition-dominated regions was delayed because of concerns 
that it would be seen as politically motivated. Incumbent politicians in Guinea, Liberia and Sierra Leone were accused of leveraging the crisis and mitigation measures to enhance political control while opposition figures were accused of hampering disease response efforts (International Crisis Group, 2015). Even though growing tensions did not lead to large-scale political violence or instability, they did complicate public health response efforts with further economic and social consequences. The UNDP (2015) reports on various effects of Ebola, suggesting that it has threatened the social fabric that glues society together.

The pandemic and the associated hardships have changed people's consumption habits; many have had to eat less than before the EVD outbreak. There is evidence that the EVD is eroding the age-long communal behaviours of the people including attendance at ceremonies, adjustment in burial rights and less caregiving to family and community members. Feelings of distrust between communities and between the people and their governments are still strong.

Large-scale outbreaks of infectious disease have direct and consequential social impacts. For example, widespread public panic during disease outbreaks can lead to rapid population migration. Barrett and Brown (2008) note that even though the 1994 outbreak of plague in Surat (India) caused only a small number of reported cases, fear led some 500,000 people (roughly $20 \%$ of the city's population, including a disproportionately large number of clinicians) to flee their homes. Toole and Waldman (1990) argue that sudden population movements can have destabilising effects, and migrants face elevated health risks arising from poor sanitation and nutrition, as well as other sources of stress. Migration also poses the risk of further spreading an outbreak. Furthermore, outbreaks of infectious disease can lead to the stigmatisation of already vulnerable social groups, as they get blamed for the disease and its consequences. For example, Siu (2015) tells a story about how Africans in Hong Kong experienced social isolation, anxiety, and economic hardship resulting from fears of their association with Ebola.

\subsection{CONCLUDING REMARKS}

This chapter is concluded by considering some of the lessons that have, or should have, been learned from past pandemics. Colvin and McLaughlin (2020) draw three lessons from the Spanish flu pandemic of 1918. The first of these lessons is that the public health response to the spread of the disease must focus on containment - after all, deaths are linked closely to infections. The second lesson is that good information is essential for disease control, in which case they warn of a media blackout or an active disinformation campaign. They argue that the truth always comes out eventually, in which case nothing 
is to be gained from hiding it. The third lesson is that we must prepare for the economic and human consequences of the virus and act to minimise its impact.

These are words of wisdom but have we really learned these lessons? As far as containment is concerned, some countries have done rather well, but others have not. Some of the countries that have not done well cannot do well because of constrained resources. Other countries that can do well did not do well because of political and other considerations (the UK and US). The second lesson has not been learned, again because of political considerations. At one time, the President of Brazil wanted to impose an information blackout by refraining from the publication of daily reports on new cases and deaths. He actually did that until he was told not to by a judge. The third lesson has not been learned, as indicated by improper and discriminatory economic policy and healthcare systems. 